Review Article

\section{Illness of great dictators - mosaic psychopatia}

\section{Dmitrieva Elena Germanovna*}

A Clinical Pharmacict, Speciality Clinical Pharmacology, Charitable Pharmaceutical Clinic, Russia

\section{Abstract}

Psychopatia is a borderline between mental diseases and good health. One of its versions is mosaic psychopatia. For certain everyone knows, that the mosaic represents. These are the parts of diverse elements collected together. And so this disease is named after the patient shows signs of several types of psychopatia at once. It is known that Historic figures such as Ivan Grozny, Hitler, Stalin, Putin and other dictators have suffered from this disease.

\section{More Information}

*Address for Correspondence:

Dmitrieva Elena Germanovna, A Clinical

Pharmacict, Speciality Clinical Pharmacology, Charitable Pharmaceutical Clinic, Russia,

Email: cyrix2003@mail.ru

Submitted: July 20, 2020

Approved: January 28, 2021

Published: January 29, 2021

How to cite this article: Germanovna DE. Illness of great dictators - mosaic psychopatia Arch Psychiatr Ment Health. 2021; 5: 004-013.

DOI: 10.29328/journal.apmh.1001028

Copyright: @ 2021 Germanovna DE. This is an open access article distributed under the Creative Commons Attribution License, which permits unrestricted use, distribution, and reproduction in any medium, provided the original work is properly cited.

Check for updates

OPEN ACCESS

\section{To known insane persons to persons carry}

Russian writer-prose writer Michael Bulgakov [1,2]. Dutch painter Van Gogh Vincent, it has(have) spent the rests(rest) of their lives in hospital for insane persons of people.

Spanish architect Gaudi Antonio, well known Russian writer Nikolay Gogol, as a result of its visual and sound hallucinations have been sick, is also have known to have suffered from morbid depression.

Austrian writer Kafka Frants, German philosopher Nitsshe, in their works accurately traced the idealistic relation to understand the relationship with the other world.

French writer Jean Jacque Russo suffered mania of prosecution; German physicist Albert Einstein suffered the maniacal form of a schizophrenia with frequent depressions.

It is important to notice, that according to medical and pharmaceutical ethics, public promulgation of medical certificates is forbidden, except for the people who are engaged in public activity that is an original payment for publicity. Thus, a consultation of doctors which conducted the correspondence analysis of behaviour of the president, have diagnosed: moderately expressed mosaic psychopatia's with prevalence signs of paranoid and dissocial frustration of the person.

Among the common signs of a mosaic psychopathic condition at Lukashenko, Shchigelsky has identified as:

Excessive propensity to manipulations

Suspiciousness and propensity to supervaluable ideas

Low threshold of aggressive behaviour

\section{Sadistic bents}

Neglect social norms

Absence of close friends, etc.

\section{The general description of illness}

Psychiatrists who are engaged in studying of this condition, have termed as Psychopatia). Otherwise this disease is called as the mixed frustration of the person at which prevalence of one's other psychopathological condition displays, and here the basic psychopathological syndrome is observed as unstable, and can be observed only occasionally. Unlike mental frustration, this kind psychopatia's practically does not recover and accompanies the person throughout their life.

Thus, modern psychiatrists consider, that it is possible to consider this disease congenital, as it cannot develop at mature age. As to the reasons presumably it is patrimonial traumas of the head or congenital underdevelopment of the brain. In mosaic type psychopatia's diverse symptoms in the set prevent to adapt normally for the person in a society and to correspond to psychosocial expectations of other people.

This disease of mosaic type is most dangerous for the patient, after all a combination in character of the person of such symptoms as excessive irascibility, hysteria, instability, frustration of inclinations etc. can lead to various dependency, for example, to alcohol and narcotics, as well as to sexual, game and other dependencies. 


\section{The mixed frustration of the person (mosaic psychopatia)}

Mosaic psychopatia is characterized by plural displays of antisocial behaviour. The people, suffering from mosaic psychopatia's, cannot enter into frameworks of a social life. Sometimes in psychology use other terms for mosaic psychopatia's (are-): plural psychopatia, mixed psychopatia or dissocial frustration of the person. The psychopathic person and the antisocial person (sociopath) are equivalent concepts.

\section{Disease aetiology}

Now the authentic reason of development mosaic psychopatia's is not revealed. Scientists allocate two theories for the development of disease:

\section{Hereditary predisposition;}

Influence of the social environment. Though, personally the author analyzed many families and has come to

Conclusion that the reasons are covered in a family - all problems go there

From when in a family there is no love understanding, trust. (The note of the author).

Supporters of hereditary character of disease assume dominating influence of certain sequence of genes on development psychopatia's. The role of mutations in a genotype of the person is not excluded. In favour of this theory speaks frequent combinations psychopatias with organic loss of the brain (oligophrenia, a schizophrenia, a delay of intellectual development).

Many experts pay attention, that development of antisocial behaviour is frequently influenced by craniocereberal traumas in katamnesis and the anamnesis.

At prevailing influence of the social environment in the conditions of ignoring of norms and behaviour rules development of psychopatia's without organic loss of the brain and in the absence of similar diseases in a family is possible.

Many psychologists tend to categorize these versions of pathogenetic formation as mosaic psychopatia's. It is known, that in $50 \%$ cases in the presence of predisposition the main role belongs to inhabitancy factors. Favorable conditions in a family and early inculcation of social norms reduce development of psychopathic behaviour even in case of genetic predisposition [3-8].

\section{The psychopathic person}

The term the psychopathic person is used by many doctors for the characteristic of patients with antisocial behaviour.

The mixed frustration of the person has following signs of antisocial behaviour:
1. inability to form attachment to surrounding people, including to children and parents

2. ignoring social norms and rules

3. aggression in behaviour

4. impose own thoughts and opinion on surrounding people

5. aspire to dominate in relationships

6. lie for own benefit

7. inability to plan the actions

8. unexpressed feelings of conscience

The psychopathic person cannot test sincere feeling of attachment to people, therefore the relations starts to build for the purpose of achievement of certain benefit. Thus they understand all norms and behaviour rules, but continue to purposefully ignore them.

Frequently such people skilfully are able to manipulate close and native for the achievement of the purpose. The dominating role in behaviour is defined by own desires. For sociopaths it is possible to lie for own benefit. Among them often there are the people who have made an offence. People with frustration of the person do not test feeling of fault. For own benefit they can simulate normal behaviour, but for short time.

Prominent feature of sociopaths is impulsiveness of the actions. In the life they are not able to apply for long-term goals. All actions are connected with achievement of shortterm result.

At the mixed frustration of the person social restrictions and norms are perceived as tools for manipulating with people. Sociopaths do not understand disinterested behaviour. Feelings of close and native people a little them excite. They can apply force or violence to satisfy the requirements. In relations with people sociopaths occupy dominating value with the tyranny phenomena in a family.

\section{Accompanying symptoms}

For revealing psychopatia's mosaic type of people it is necessary to be guided not only characteristic signs, but also to pay attention to accompanying symptoms. Such symptoms complicate social adaptation and allow to reveal sociopaths at early stages of formation of antisocial behaviour.

The common signs, allowing to suspect mosaic psychopatia's, are:

1. irritability

2. emotional instability

3. hardship with training 
4. inability to process labour, especially in a regular order

5. pathologically the liars write off the errors on others

6. emotional response

Plural frustration of the person can be revealed in children with antisocial behaviour at school. As a result, such children badly study and differ severe behaviour. They cannot normally react to external factors, therefore try to choose always for themselves a role not of a victim, but a predator. Emotional response is a mechanism of protection at which the child loses the frightening scenario for the purpose of replacement of a passive role by the active. The victims they choose are weaker children.

In early diagnosing mosaic psychopatia's the important role is given to school psychologists who should work with children on a subject sociopathia's. It is necessary to give special attention to children from unsuccessful families where in children from early age the antisocial behaviour takes root.

\section{Kinds mosaic psychopatia's}

In psychological practice it is accepted to allocate two forms psychopatia's:

1 form - For active psychopaths - the behaviour without internal and external delays is characteristic. Sociopathas do not constrain the behaviour and do not consider it necessary to observe laws and rules in a society. Such people some time can behave normally, especially, when it is demanded by a mode or supervision of authoritative people (hospitalization or imprisonment). In the absence of supervision active sociopathas again conduct an antisocial way of life. Presence of morals and conscience in them is not observed.

2 form - Passive sociopaths in the life are guided by the certain arch of rules which replace with ones conscience and other feelings. Most often such people are attached to religion and actively observe all religious laws. Such people often have an ideological behaviour when for imitation they choose an ideal or the authoritative person. These people simply obey certain laws without comprehension of humanity of the acts. At deprivation of an ideal and change of a habitual way of life passive sociopaths can show antisocial behaviour.

\section{Supervaluable ideas in mosaic psychopatia's}

There is such version mosaic psychopatia's in which in the person is combined with not only symptoms of various types psychopatia's, but also a schizophrenia. Such mix of signs can lead to occurrence in the person of so-called supervaluable ideas which the patient wishes to realize by all means during a life. Any idea arising in a head, receives the special importance in his eyes, therefore they can spend all forces and energy for their realization.

People who suffer this disease, hardly find common language with associates. However unlike apathetic and depressive people who become reserved, with people of this type are very difficult in dialogue. With them even it is hard to be in one premise. They are capable to deduce from themselves and are very quiet people.

\section{The diagnosis and illness picture}

The psychiatry is engaged in revealing and treatment of patients of genuine diseases. However even to the most skilled experts at times is difficult to diagnose mosaic psychopatia's as signs concern not one concrete kind, and at once to several, and in different variations. After the first inspection to the psychiatrist can sometimes seem, that it is - not psychopatia, but schizophrenia. Besides, the semiology constantly varies, is unstable, and only the expert of the top skills can make the exact diagnosis. At the given kind of disease of the patient the combination paranoiac frustration with the raised irascibility can be observed.

Other signs - constant complaints to injustice in relation to the person from all and everything, and also on unconsciousness of associates, for example, housing and communal services, teachers at school, medical staff etc. Such people at the slightest pretext can address in court, and in case of a sentence inconvenient for them, will appeal still for a long time after the court's decision. In Russia there are too much psychopaths that to the normal person difficultly happens can true to be in this society.

Often enough in mosaic psychopatia's the patient has a combination in a root of opposite types: hysteroid, excitable, schizoid and asthenic. This dangerous mix of symptoms can lead to schizophrenia development.

However at diagnosis definition first of all the doctor should base on research of behaviour of the patient, and his symptoms. After all, answering questions of tests, the patient can be insincere.

\section{The list of symptoms}

Studying character and behaviour of many of great dictators, psychiatrists have come to conclusion, that some of them, namely, Mussolini, Hitler, Stalin, Putin and others suffer this sincere disease.

Following lines (symptoms) concern them:

1. thrust to a manipulate people of the environment

2. egocentricity

3. idea about the theory of Plot which mentions them in the direct image

4. excessive suspicion

5. inadequacy in perception of the world 
6. nomination supervaluable ideas which need to be realized

7. strong self-esteem

8. pathological boasting

9. non-recognition own fault

10. falsifying the truth in the mercenary purposes

11.lack feelings, as sympathy and empathy, and at times and sadistic bents

12. inability to incur responsibility

13.pessimism

14. desire to enter into the same water, that is the inability to benefit by negative experience twice

15.lack friends and adherents

16.inability to love

17.hardship in dialogue with people

18. scornful the relation to social norm, etc.

The characteristic of the mosaic psychopathia's

The main distinctive line of the psychopath is an absence of feelings such as sympathy, and realization of fault. In this the main reason is the fulfilment of evil deeds of mentally sick people.

There is a certain characteristic which allows to create the description of the psychopath's:

1. Lack of understanding feelings of fear: For a healthy person it is not difficult on a mimicry and gestures to see fear at the person. The main minimum displays of fear consider: expansion of pupils, opening of the mouth and raising the eyebrows, all the rest is felt intuitively. And so, the psychopath, seeing a similar mimicry is simply incapable to distinguish fear in the person. For such perception, can be answered by amygdala of the brain. In a sick person its cover is much more thin, and the volume is less, than compared to a healthy brain therefore, there is no understanding of fear. Thus the psychopath is capable to distinguish and feel all other feelings, but not fear.

2. Insurmountable desire of manipulation over other people: The desire to kill and manipulate arises in such group of patients as a result of excessive development of dopamine. This substance is developed in a brain and is responsible for the pleasure centre. Psychopaths become dopamine addicts, thirst of emission of a new dose of substance in a brain and satisfaction receptions, thus, provokes them on fulfilment of murders, violence or aggression display.
3. Sympathy button: Interesting research was done by neurologists from University of Groningen to Holland in which result has come to a following conclusion. Psychopaths do not feel compassion and sympathy, another's pain, they are not capable to rise to the place of the person to whom it is bad. But, despite this they have moments when they can be goodnatured and affable but only when it is necessary for them. If a healthy person is feeling of sympathy is inherent always at people sick of these pathology it is in a condition of switched off till the moment necessary to them. That is why maniacs and murderers often are very affable in the beginning with the victim, and then are blood-thirsty to finish them.

4. Professions is drawing psychopaths: Kevin Dutton the researcher from Oxford has defined the list of trades where the greatest quantity of deranged people are concentrated. And to the surprise when the in the lead position was occupied not with lawyers, policemen and at all, doctors, and a post general director was. The held testing for volunteers from sharks of business has shown, that one of 25 people is a psychopath. And they have achieved such heights not for the professional qualities, and strangely enough to the charm, that besides confirms the theory about inclusion and deenergizing of feelings. Maniacal thirst of manipulation and terror pushes such people to hold high administrative posts, including not only in business, but also in state domination.

Attention! In Russia it not absolutely so. In armchairs psychopaths of those who has toadied (long put sat in an armchair more low, did to the chief personal services) or on type - a family shelter. For example, Niconov (the deputy and the TV presenter) - grandson Molotov's.

Mosaic psychopathia and a schizophrenia are little bit different things though some unite them as one. Psychopathia's can have schizoid signs and similar displays, but the diagnosis is different. Danger of a pathology depends on shown symptoms. One become ingenious writers, artists and poets, others ruthless murderers and maniacs. In any case, the similar condition demands consultation and the further control of the expert, after all only then it is capable to distinguish genius from potentially dangerous murderer.

Attention! At the mixed frustration of the person the basic psychopathological syndrome either is not defined, or is not proved, that one thus prevail, other displays pathological symptoms.

Diverse the symptoms for peculiar psychopathia's of mosaic type, leads to that to the person is improbably difficult to get on in a society, to adapt to unwritten social requirements.

Following character traits which in a combination to any kind psychopathia's can make of the person of the maniac, the tyrant or the murderer are allocated:

1. emotional dullness 


\section{2. fast excitability}

3. epileptoid

\section{As it is shown mosaic psychopathia}

Mosaic psychopathia - frustration of the person at which the person has a set of signs of various types (of) psychopathia's, leading to the expressed difficulties of the social adaptation.

At the mixed frustration of the person the basic psychopathological syndrome either is not defined, or is not proved, that one thus prevail, other psychopathological displays.

The mixed frustration of the person: signs of a combination of various types of psychopathias

If the character of the person hysterical, unstable and explosive character traits are combined, there are infringements of inclinations, then such explosive mix can become a basis for occurrence of various kinds of dependencies (alcoholic, narcotism, game, sexual and others).

Frustration of the person of the mixed type in which signs of schizoid frustration of the person and psychasthenia lines are combined, often is soil for occurrence of supervaluable ideas. Such people erect any usual thoughts, ideas in the category especially significant, in every way try to realize the ideas. In people who show signs of schizoid frustration of the person are combined with psychasthenia, it is very difficult to get on in a society. They are not able to come into contacts to associates, but at the same time anywhere and everywhere try to realize the supervaluable ideas.

Combination of signs paranoiac psychopathia's with the raised irascibility; initiate - a basis for litigious-verwandte behaviour. Such people constantly aspire to defend the, ostensibly, the infringed interests. They complain in various instances, write every possible denunciations, statements of claim bring an action. And then again and again will appeal against any decision of the court.

If at the person simultaneously there are initially has opposite signs of psihopatization's (hysteroid psychopathia's and schizoid, excitable and asthenic) then the doctor should be on guard. Often enough such combination of opposite signs in the subsequent pours out in schizophrenia development.

\section{Stratification of organic frustration of the person}

Meets also such, that organic frustration of the person accumulates on signs of congenital mosaic psychopathia's. The given pathology is got set. Set of the diseases accompanied by loss of the brain, can lead to that there are essential changes in already diagnosed person. The most widespread reasons of development of organic frustration of the person - craniocereberal traumas, an epilepsy, neuroinfection, an alcoholism. That is why the author is against vaccination, after all this introduction in an organism of children of viruses and bacteria.
If to illness the person had signs of the mixed frustration of the person, it was difficult to it to find common language with associates after beginning of disease of the brain, these signs become even more expressed, and the person - even more intolerable.

There can be following signs of illness - ability to do purposeful activity decreases, can appear (or to amplify) emotional instability, attacks of causeless rage or euphoria. Such people speak long, in details, however actually they repeat same. In statements ideas can sound crazy.

\section{Treatment ways}

To cure mosaic psychopathia's in some cases it is possible with medicamentous methods. But doctors-psychiatrists resort to the given kind of treatment only in very serious cases of disease when the patient tests genuine sufferings, especially at contacting with surrounding people owing to what there are conflict situations. The choice of preparations depends on what kind psychopathia's prevails.

For example, at supervision of the patient of hypererethism which can lead to hostile actions in relation to people, and also origin at it absolutely crazy and obsessions, are by all means appointed antipsychotic drugs, and in a combination to sedative preparations. And for the patients, suffering fast change of mood, treatment occurs by means of anticonvulsant means. The purpose of the expert - to direct treatment of the patient to such channel to avoid an aggravation of a condition and illness progressing, it is even better - to cure.

Sometimes the psychiatrist and Clinical Pharmacists should treat similar patients by means of tranquilizers (in case of extreme excitability) or, on the contrary, to appoint energizers. Naturally, in acceptance of preparations it is necessary to refuse receptions of alcohol and drugs completely. If illness proceeds in easier form the expert can appoint only vitamins.

\section{Treatment}

In itself mosaic psychopathia does not demand treatment, it is necessary to address for medical aid only in case of an aggravation of personal frustration. Indications for the manipulation to the expert - occurrence of the expressed excitation, crazy ideas, obsession, a depression, and then it is necessary to receive treatment of psychopathia's.

If the person had a stratification of organic frustration of the person on already available mixed psychopathia's then treatment is necessary. It is problematic - not to admit the further progressing of illness, as much as possible to keep social adaptation of the person. Depending on present symptoms - tranquilizers, energizers, normotimics means, vitamins can be appointed as antipsychotic drugs.

\section{Mosaic psychopathia and the law}

Quite often resulting in antisocial behaviour is law infringement as a result deviant behaviour. 
Kinds deviant behaviour:

Infringement of the legislation in the field of administrative or criminal law conduct to occurrence of consequences in the form of a sexual attack, swindle, hooliganism and in the heaviest cases of murder.

Infringement of antisocial norms and rules does not bring direct harm to surrounding people, but can indirectly be reflected on them. Evasion concerns such behaviour from labour duties, small dirty tricks (to hide the order, a bag) or inadequate behaviour.

And their behaviour can be reflected badly in others. For example, Ministry of Health of Russia bypassing the law on inoculations [9], has thought up obligatory inoculations though, at us for health of children parents answer. And only they can decide - to do to children tests Mantoux and inoculations or not to do. Besides, reaction Mantoux - not specific test, it does not give the exact answer, and complications can give much! More reasonably - to make the diaskin-test. Or to do nothing. There is a photoroentgenography.

This right of mother. And bureaucrats revenge the woman. It is revenge for refusal. Desire to impose the opinion that is inadmissible.

In Pavlovsk Посаде for refusal to put tuberculine test (reaction) Mantoux to the child mother Ilatovskya's Elena without preliminary survey compulsorily was taken away in psychiatric clinic on treatment on a denunciation of the director of lycée by VV Tikhonov’s №2 names on of Pavlovsk Posad Serova's Marina Borisovna and the head physician of polyclinic Marchenkova's (on Lenin's street, 56), have informed to Russian national line the sources familiar with a situation.

The lawyer in law infringement to Elena Ilatovskya's didn't start up, documents and the bases for hospitalization are not given.

Lines of the psychopathic person often lead to their fulfilment of various crimes. However sociopaths never regret for perfect infringement of the law, and only that have caught them. But, I hope, that all will catch and will punish them.

In the social plan such persons can be realized as leaders of criminal grouping or religious sects. Or get to the state structures. The destiny of many people, suffering mosaic psychopathia's, occurs in connection with the use of drugs or alcohol. Dependency is formed only for satisfaction of own desires.

\section{Diagnostics}

In the international classification of illnesses MKD-10 there is no diagnosis of mosaic psychopathia's. MKD-10 contains section - personal frustration. Here there are possible diagnoses of psychopathic frustration of the person.
At mosaic psychopathia's the diagnosis is established in the presence of following signs (not less than three):

1. indifferent in relation to close people

2. irresponsibility and the scornful relation to social behaviour

3. inability to form attachment

4. low a threshold of restraint of the aggressive behaviour and the short period frustration

5. lack feelings of fault

6. reasons to justify of their behaviour and charge of other people

If it is established, at least, three sign the expert can easily diagnose dissocial frustration of the person or mosaic psychopathia. Sometimes for diagnostics experts need to look through records of the school psychologist about presence of disputed behaviour. By an additional sign emotional instability and irritability can be considered.

But it is necessary to notice, that the estimation of behaviour of each patient is considered individually. Parities of religion and the law for formation of antisocial behaviour are for this purpose made.

There are some more criteria entered by the American Mental Association which presence is considered obligatory for the diagnosis mosaic psychopathia:

1. discrepancy to social norms and rules

2. hypocritical behaviour

3. lack planning in a daily life

4. aggressive and rigid behaviour

5. susceptibility itself and associates to unjustified risk

6. irresponsible behaviour on work and in a life

7. lack pity to associates and indifferent behaviour

The diagnosis can be established only to full age people. Thus it is necessary to consider signs of psychopathia in a person aged above 15 years.

In the presence of accompanying mental diseases the proof of presence of antisocial behaviour during the well-being periods is necessary. For example, in an is maniacal-depressive syndrome the behaviour in manias and depressions is not considered. For revealing of difficult cases the commission with carrying out of psychological examination for exhibiting of the final diagnosis is required.

\section{Treatment}

Inherently psychopathia is a specific feature of the 
constitution of the person. Pathology therapy is directed not on change of the person of the person, and on updating of its social behaviour.

Treatment mosaic psychopathia is spent by psychotherapists.

Basis of activity of psychotherapists is carrying out of psychotherapeutic sessions during which time the psychological portrait of the patient is made. Experts with the higher medical or psychological information which have ended special curriculums can be psychotherapists. The purpose of psychotherapeutic sessions is correction of social behaviour.

The author personally applies psychoanalysis on Assagioli (the note of the author). In the course of psychosynthesis it is necessary these parts, these isolated mental processes, desires, aspirations, before, - to realize, and then - to unite. But not easier to unite, and to unite so that there was a harmony. It works. But I apply this method in the updating - at first classical psychoanalysis, as a diagnostic technique, instead of as practical, then already - a method on Assagioli.

Kinds of the psychotherapeutic help:

Patients with mosaic psychopathia's very seldom address for the help independently. To visit their psychotherapist, obliges the law at stay in correctional facilities. On sessions the expert performs psychoanalysis with revealing of the basic problems of the patient.

Many practice group sessions when the whole group of patients with similar behaviour show up. On sessions they find out the reasons of antisocial behaviour and consider various ways of their decision.

One of psychoanalysis problems is the hostile spirit of patients who consider, that the expert specially wishes them to discredit in the opinion of surrounding people, therefore a psychoanalysis basis is the establishment of confidential relations between the expert and the patient.

Sometimes at the raised aggression, medicamentous therapy is applied.

But the life has shown, that display of antisocial behaviour cannot be cleaned by means of medicines. To impart a normal social image it is possible only with use of psychotherapeutic sessions and herbal medicines.

Sometimes people address for the help to experts when they notice the various perception of world around from other people. Independently understand a problem essence such patients cannot, therefore frequently stay in a confused condition.

Therapy psychopathia's is directed not on change of the person of the patient, and on development of its ability to adapt for conditions of the social environment. Decrease in level of uneasiness and emotional aggression helps patients to operate the behaviour.

In MKD-11 division of frustration of the person on types, the archaic mosaic are eliminated. In the subsequent there will be only degrees, and, since акцентуаций which for today are norm variants.

Psychoanalysis and psychodynamic direction of psychotherapy are the direction second for efficiency and in case of treatment and correction of frustration of the person, on the first place again kognitivno-bihevioral psychotherapy, but if frequent it does not work. The patient does not hear reason of the expert.

In opinion it is very wide the researcher of frustration of person Teodor Millon's known in the USA (T. Millon), the author of the original concept of frustration of the person, the last, being put into words VA Geodakjan's, it an evolution touchstone. If they were not to live it would be much more boring and we would live at absolutely other level of a civilisation.

That type which at LN Gumileva is called as a passionarity or passionary, in many respects, coincides with totality and PB Gannushkin's stability. Social disadaptation, since certain level of a social ladder, - ceases to show itself in this quality. The above on a career ladder, that it is more psychopathia's (the note of the author).

There are other problems of hyperdiagnostics of frustration of the person.

Now as a matter of fact:

1. Social value of the person is a little connected with presence/absence of mental frustration which all history of mankind confirms.

Manihejsky delirium, also delirium Manichaeism crazy Manichaeism - manism (an armour. delirium manihaeismum) - most sharply proceeding version of antagonistic delirium, its description for the first time surfaces in 1922 the French psychiatrists M Dide and P Giraud. Some psychiatrists are inclined to identify in general antagonistic and Manihejsky elirium, also sometimes it carry to versions of delirium of greatness. In the Soviet and Russian psychiatry there is a classification practice Manihejsky delirium as one of stages oneiric conditions.

It is considered, that Stalin and Lenin - diagnoses.

To take letter Chaadaev's after which it recognised as the madman and have forbidden it to write. But letters are not a recognition of presence of mental disease.

At us nature such, it is necessary to express precisely thought, and not one... 
At therapists - all is clear, ours oh sometimes 000...so understand is orgasm or an agonal sigh...

Social value of the person is certainly defined by society.

For example. Today we remember Victor Hrisanfovich Kandinsky not that he suffered a schizophrenia, but for his books, first of all, his book pseudo-hallucinations which he has written, mainly leaning towards on introspection (introspection).

And examples such set. By the way, somatic health also is a little connected with social value of the person and his heritage.

The closest on borders of criteria of mosaic - Mixed and other frustration of person F62 and some other.

The border line between health and mental frustration is washed very away, as one academician has once told: it seems to me that declared amnesty in psichhospitas!

Studying character and behaviour of many of great dictators, psychiatrists have come to conclusion, that some of them, namely, Mussolini, Hitler, Stalin, Putin.

Last name is honorary mention and especially terrifying.

Putin why in dictators have been defined? It is on the lawful bases is selected by the majority democratic by in a peace time. But now become the dictator.

This I remember - there is on the TV screen Eltsin's B.N.'s semidrunk physiognomy and declares about the following: Everything, has got tired. I retire. The successor I appoint Putin V.V.!

Here to you and it is selected by the majority of the population. As!!!

Hitler democratically as has been chosen, but then usurped the power, became the dictator.

Grozny inherited the power, each tsar was the dictator under laws of that time.

Stalin got out according to operating in those days procedures, but then became the lifelong dictator.

According to the Constitution the impossibility of execution of the functions of the president on this post to the elections of the prime minister is appointed, Putin was the prime minister.

\section{Also what not so was?}

Putin was the prime minister at that time and he was appointed to the post the president.

But then, it is not necessary to forget and write about it, to put it mildly, notorious not the truth about national voting and unanimous elections the present guarantor!!!
At us memory not lost it's, we perfectly remember, who of that then did of a nomenclature top and, whom-where and when have appointed.

Yes in general, psychiatry - the selling maid of imperialism! We here, you understand, persistently, super valuable we build communism № 2, and us offend by a mosaic! Psychiatristsimperialists already have destroyed in due time № 1 , and now strive to ruin also Russia, masking false care about mental health of the Russian population.

Whether it is dictator Putin? I think, that it is no more, than Brezhnev with Khruschev, and it is exact no more than Yeltsin. And here the psychopath (let even mosaic) it precisely is not.

As to Stalin, Bekhterev or A.E. Lichko's diagnosis (paranoiac psychopathia's) I see more proved and approachable.

The psychiatry - as a science too is created by people, as well as the policy, and was at all times time rather conjunctural, is subjective and inclined to manipulations. At any leader it is possible to find weight pleaseth and objectionable to public of properties and qualities. Unless is not present?

So can be, more effective would be to change tactics of own behaviour? The truth is known after all, that if to the person said all the time, that its a pig, eventually, it grunts ... And, if to trust in the person and to support, other and mountains will curtail. While all of us sit and we wait, when someone will make to us WELL. Also we spit in the one who something tries to make...!!!

And among signs psychopathia's, for example, the such:

1. difficult with training

2. inability to plan actions

3. inability to labour process, especially in a regular order

4. pessimism

5. manipulation

It is improbable, that with such signs (first three) it is possible to reach power tops. But for Russia bad - it is always possible!!! And armchairs get just psychopaths, at least.

If you can not win fairly simply win!!!

Everyone can be the psychopath. To behave as the psychopath anybody has not the right! Psychopathia it is shown in decompensations.

Psychopathias is great variety.

There is a Triad Psychopathias Gannushkin's-Kerbikov's

1. severity frustration of the person and behaviour to degree steady social de adaptation 
2. relative stability and small convertibility of frustration of the person

3. totality frustration of the person, mentioning all its aspects, beginning from requirements, inclinations and finishing ideals, outlook and values of the individual

But, while decompensation has not occurred, while the psychopath in a condition of to supervise, distinguish the psychopath from normal it is possible only through careful psychiatric inspection by means of clinical psychology. And that - is the question, difficultly!

The main thing to understand, that the concept norm of psychiatry is an indistinct concept and not a point on planes, and an extensive field with indistinctly outlined borders behind which are totality psychopathia's! And they migrate through these borders fall outside the limits towards this or that form psychopathia's come back in limits of relative norm and it is possible to name them accented persons (with strangenesses), or in general look normal, but at any moment can considerably change, and here and then... The Psychopath to overpersuade it is practically impossible!, therefore Cognitive the Psychotherapy also does not work. In general, the muzhik married the kind and appeasable woman, and after wedding - a snake!

But also absolutely normal people are not present, and the they are closer to absolute norm, the more boringly and not more interestingly they! Though, it too is not unequivocal. Well, there is no highlight, there is no unpredictability!

And, here, behind borders psychopathias the huge field of true loonies - a schizophrenia (them too already begins much!), bipolar frustration - too it is a lot of them and other...

\section{About history}

We know about Ivan Groznoy's difficult character only from English historians.

Hitler, by the way, mass-media has been recognized by the person of year if it suddenly does not begin war would remain the greatest figure of Germany.

Well, and Stalin, in what its abnormality? What it had an inhuman working capacity and strategic mind? Or absence of self-interest? Probably, its verses do not like?

Conclusion-all patriots of the country psychopaths?

You cannot get - spit it out!!!

What to do???!!! We not amendable - we trust in reason. The truth in a word is reason we put only the representations about the reasonable. Here also we receive. To think it is possible differently, but each time funny for the opponent. It is not necessary to edify and teach, how vests try.

Well-well! Putin, means, suffered in the childhood, his two younger brothers have died in the family, parents have brought up it already, being, in old age. Or it has recovered?

Putin in 2004 has made to himself a quota on elections no more than $25 \%$, therefore in Russia $25 \%$ of the population, instead of the majority have voted. If the quantity of the population of 150 million we subtract children till 18 years, turns out 120 million. out of which 56 million has voted). It is not $76 \%$ as Blown? on elections.

If the pain (cardialgia) acts in film validol, it means stressful a pain, and the person demands consultation of the psychologist and the psychotherapist.

If a pain - result of organic deviations it is necessary to survey and treat in the field of therapy. And, as mentality, and somatic's it is possible to treat with herbal medicine (the note of the author).

Take for yourself a habit to begin day from a question:

What I can make today to feel happy?

Fill the life with pleasure, change the behaviour which does not bring to you satisfaction. Only such daily actions, instead of searching of a magic tablet, will help you to raise a selfestimation, to find confidence of the forces, and to be shone by a next world which will give rise in you to such desired condition of happiness. And this condition is infectious. It will be transferred also to other people!!!

\section{Conclusion}

To pass the law about mobbing - absence of psychoterror on work and houses.

To pass the law against physical violence on work and houses.

Treatment of mosaic psychopaths by methods to carry out herbal medicine (aeroionophytotherapy, an aromatherapy and psychotherapy).

But unfortunate is the man- (Vladimir Putin) went on. Back in 2004 , he made it so that only $25 \%$ of the population can vote and he will sit on his throne always. 56 million people voted, which is not $56 \%$ of the population. In Russia, there are 145150 million people, some of them children under 18 years of age. But there has been no census since 2002. Intentionally or not? It's an open question.

What has Putin done in 20 years of rule? The population lives below the poverty line, given only a living wage of products. And live on this money, as you want. It is useless to reach the President by letter. Helpers won't let you in. This shows that he doesn't care about people. Putin's daughters have other surnames and patches like the President's.

Delusions of grandeur there are. 


\section{References}

1. Mashkov VN. Differential psychology of the person: the Manual. The Publishing House. Peter. 2016; 52.

2. Zhmurov VA. Psychiatry. The encyclopaedia. T/O. Neformat. 2016.

3. Under GV. Morozova's edition. A management on psychiatry. M: Medicine. 1988; 304-305.

4. Tiganov AS, Snezhnevsk AV, Orlovskaja DD. The Management on psychiatry in 2 volumes/Under the editorship of the academician of the Russian Academy of Medical Science AS. Tiganov's, M: Medicine. 1999; 562: 563-564.

5. Schmeck K, Schlüter-Müller $S$. Persönlichkeitsstörungen im Jugendalter. Springer-Verlag. 2009; 5: 140.
6. Schneider K. Die psychopathischen Persönlichkeiten/Hrsg. Aschaffenburg G. Leipzig und Wien. Franz Deuticke. 1923.

7. World the public health services organization. Section $V$ «the International statistical classification of illnesses, traumas and causes of death of 9th revision», adapted for use in the USSR - M, 1983. 45-49.

8. Gannushkin PB. Clinic psychopatias, their statics, dynamics, systematisation - Nizhni Novgorod - Publishing house of the Nizhniy Novgorod state medical academy. 2000; 124.

9. Ministry of Health of the Russian. The order of Ministry of Health of the Russian Federation from 27.05.97 № 170 (From 12.01.98) «About transition of bodies and establishments of public health services of the Russian Federation to the International statistical classification of illnesses and the problems connected with health of $\mathrm{X}$ revision» zakonbase.ru. 2018. 